\title{
Assessment of Nurse's Knowledge and Practice Working in District Hospitals at Minia Governorate about Neonatal Hyperbilirubinemia
}

\author{
Sanaa Mahmoud Ahmed ${ }^{1}$ and Mohamed Hani ${ }^{2}$ \\ ${ }^{1}$ Lecturer of Pediatric Nursing Faculty of Nursing, Minia University \\ ${ }^{2}$ Head of Premature Units of Minia Governorate, Ministry Of Health
}

\begin{abstract}
Background: Neonatal hyperbilirubinemia occurs in about $60 \%$ of newborns. If not managed properly, it can progress to severe neonatal hyperbilirubinemia (SNNJ) leading to death or permanent disability.

Aim: To assess nurse's knowledge and practice about neonate with hyperbilirubinemia.

Subjects: 41 nurses working in nine districts hospital in Minia governorate each district one hospital and from Minia district 3 hospital.

Settings: The study was conducted on nurses working in11 governmental district hospital in Minia governorate Results: $58.5 \%$ of nurses below 26 years old with mean age $25.8 \pm 4.3$ years and $63.4 \%$ live in rural area. As regard years of experience in neonatal intensive care unit $39 \%$ of nurses, $48.8 \%$ of nurses has experience $<5$ years in other departments, $70.7 \%$ of nurses received previous training in neonatal care. $92.7 \%$ of nurses have Satisfactory knowledge about hyperbilirubinemia. As regard relation between personal \& socio-demographic data and nurses' knowledge regarding hyperbilirubinemia it is shown that Years of experience in NICU and Years of experience in other department have high significant as $* * P-$ value $\leq 0.01$ and Age / years $* * P-$ value $\leq 005$ and for Training is significant $* P-$ value $\leq 05$.

Conclusion: Based on the finding of the present study one can conclude that the highest percentage of nurses had satisfactory knowledge, while minority of nurses' had unsatisfactory score regarding hyperbilirubinemia in neonates. Also the majority of nurses' were competent regarding practices related to hyperbilirubinemia. Recommendation: Establishment of in-service educational program to provide continuous education for nurses working in the neonatal intensive care unit aiming to refresh their knowledge, practice for care hyperbilirubinemia in neonates with and for the new assigned nurses to improve their knowledge and practice.

Keywards: hyperbilirubinemia, neonatal, nurse's knowledge \& practice
\end{abstract}

\section{Introduction}

Neonatal hyperbilirubenemia is a common condition affecting newborn babies. Two thirds of human neonates develop clinically evident indirect hyperbilirubinemia in the first few days of life making it the most common clinical condition in the newborn requiring evaluation and management. Watchko and Maisels (2002)

Neonatal hyperbilirubinemia occurs in about $60 \%$ of newborns. If not managed properly, it can progress to severe neonatal hyperbilirubinemia (SNNJ) leading to death or permanent disability.Abai G, et al (2011) and Canadian pediatric society (2007). Su and Pahang, (2014).

Neonatal hyperbilirubinemia which is yellow coloration of the skin and sclera in newborns from the accumulation of unconjugated bilirubin occurs in most newborn infants and it is the most common condition that requires medical attention in newborns. Slusher, Olusaniya (2012)

Most jaundice is benign (physiological) and usually need no treatment as it resolves within two weeks. However, the diagnosis of physiological jaundice is retrospective because sometimes jaundice can start with bilirubin in the physiological range and then escalate or become prolonged or show signs of cholestasis. Slusher, Olusaniya (2012) and American Academy of Pediatrics(2004).

More importantly is the neurotoxicity (acute bilirubin encephalopathy) or death in newborns and lifelong neurologic sequelae in infants who survive (kernicterus) from excessive rise of unconjugated bilirubin. For these reasons, newborn infants with jaundice must be identified early and the level of jaundice monitored to identify those who might develop severe jaundice, acute bilirubin encephalopathy and kernicterus Adebami (2011) and Queesland Maternity and Neonatal Clinical guidelines Program (2012).

It is known that missed diagnosis of jaundice, trivializing all cases of neonatal jaundice, poor monitoring, and prescriptions of wrong and ineffective medications for jaundice has been found responsible for the persistence of acute bilirubin encephalopathy and cerebral palsy in the sub region Adebami (2011). Among the babies who presented late with acute bilirubin encephalopathy in a teaching hospital, about $80 \%$ were seen by at least a health worker $24 \mathrm{hr}$. before the brain damage and were given ineffective prescription, wrong counsel and reassurance. Adebami (2011). Primary and the secondary health facilities and the workers are the 
closest health care providers to the community in terms of availability, accessibility and affordability. The role of primary and secondary health care levels is very critical to neonatal hyperbilirubinemia management. Parents heavily depend in most cases on the advice and care being provided by these facilities without cross checking whether they are right or not. Adebami , et al., (2015) Nurses play a very important role in caring the baby during phototherapy. Of all care givers in the NICU, nurses usually spend the most time at the baby's bedside.

Angel (2015)

\section{Aim Of Study}

This study was designed to assess nurse's knowledge and practice about neonate with hyperbilirubinemia Research question:

What are the level of knowledge and practice of nurses about neonatal hyperbilirubinemia?

4.1.Subject:

\section{Subject And Methods}

The subjects were 41 nurses working in nine districts hospital in Minia governorat each district one hospital and from Minia district 3 hospital.

\subsection{Settings:}

The study was conducted on nurses working in 11 governmental district hospital in Minia governorate which are Dermoas general hospital, Mallawy general hospital Abokorkas general hospital, Minia general hospital, Minia 25 January hospital, Minia Insurance Hospital, Samalout general hospital, Mattay general hospital, Banimazar general hospital, maghagha general hospital and Eledwa general hospital.

\subsection{Study design:}

Descriptive design was used for this study.

\subsection{Study design:}

Descriptive quantities design was used for this study.

1.5. Tools of data collection: Data of this study was collected using the following tool:

A self-administered questionnaire format was the tool of the study designed by the researcher in Arabic language, which is consisted of the following parts:

Part (I): Nurses sociodemographic characteristic in the term of age, qualification, years of experience in NICU and other departments and attendance of previous training courses?

Part (II): Nurses' knowledge related to knowledge of nurses about neonate hyperbilirubinemia as definition of hyperbilirubinemia, causes, manifestation, investigation of hyperbilirubinemia, bilirubin level therapeutic management and complications.

Part (III): Nurses' knowledge related to nurses care (practice) of neonate with hyperbilirubinemia as definition of phototherapy, ninor side effect of phototherapy, nursing care for neonate receiving phototherapy

Scoring system: There were 51 questions on knowledge .To measure the adequacy of knowledge is based on passing mark of 50\% and above. Inadequate knowledge is measured by mark of below $50 \%$.

\section{6. thical consideration:}

A written initial approval was obtained from the research ethical committee of the faculty of nursing at Minia University. Oral informed consent was obtained from the nurses participate in this study. Each assessment sheet was coded and nurse name or hospital name not appeared on the sheets in the purpose of anonymity and confidentiality.

1.6. Methods:

The study was carried out in three phases:

Phase (1): Preparatory phase:

* An official letter of the study approval was obtained from the dean of the faculty of nursing at Minia University to the vice ministry of health in Minia governorate and from the head of training of premature units all over Minia governorate hospitals.

* This letter was including a brief explanation of the objectives of the study and permission was requested from each nurse to carry out the study.

* The study tools were developed by the researcher after an extensive review of the relevant literature.

* Validity and Reliability: The tools were tested for content validity by 5 experts of academic medical and nursing staff from faculty of nursing at Minia University. Modifications were done accordingly, and then the tools were designed in its final format and tested for reliability by using internal consistency for the tools measured using Cronbach test, the tools proved to be reliable (0.73).

- Pilot study: A pilot study was conducted on $10 \%$ of the study sample (4 nurses) in a selected setting to evaluate the applicability \& clarity of the tool. No modification was done in the study tool based on the pilot study. This sample was included in the study sample. 
Phase (2): Implementation phase (Study Procedure):

- Ethical consideration: A written initial approval obtained from the research ethical committee of the Faculty of Nursing, Minia University. An oral permission for voluntary participation was obtained from nurses and purpose of the study was explained. The researcher initially introduced himself to all persons and they were assured that the collected data would be absolutely confidential. Persons were informed that participation is voluntary and that they could withdraw at any time of the study. Confidentiality of the nurses' data was ascertained. Confidentiality and anonymity were assured. Nurses' names were coded for data entry so that their names could not be identified.

- Data were collected within 6months .Two day/week at official school time from 8 Am: $12 \mathrm{pm}$. The investigator met the subjects at their work place. The time spent to fill the questionnaire ranged between 20 to 30 minutes according to the needed explanation. Measures were taken to protect ethical rights of subjects. Voluntary participation, confidentiality and anonymity were assured.

The results of this study showed that

\section{Results}

Table (1) show that $58.5 \%$ of nurses below 26 years old with mean age $25.8 \pm 4.3$ years and $63.4 \%$ live in rural area. As regard years of experience in NICU $39 \%$ of nurses, $48.8 \%$ of nurses has experience $<5$ years in other departments, $70.7 \%$ of nurses received previous training in neonatal care. $75.6 \%$ of nurses are married and 90.3\% of married nurses have children. Table(2) Illustrate that $97.6 \%$ Define hyperbilirubinemia as increase bilirubin level in the blood, As regard causes $85.4 \%$ mentioned that Rh incompatibility. $100 \%$ of nurses know that Yellowish discoloration in the skin is manifestation of jaundice.

Table(3 ) $53.7 \%$ of nurse mentioned that therapeutic management for hyperbilirubinemia are conventional phototherapy, extensive phototherapy, blood exchange and breast feeding.

Table(4) As regard complication 87.8\%, 80.5\%, nurses' knowledge regarding to complication for hyperbilirubinemia, was Vision disability and Hearing disability.

Table(5 ) For nurses' knowledge regarding to phototherapy $90.2 \%$ of nurses defined phototherapy that is Application of fluorescent light to the naked baby except genital organ and eye

Table(6 ) as regard Minor side effect of phototherapy Hyperthermia Increase metabolic rate Bronzy baby syndrome andDehydration $97.6 \% 95.5 \% 95.1 \% 95.1 \%$ respectively.

Table(7 ) As regard Nursing care for infant receiving phototherapy 100\% of nurses Assure effective of phototherapy, Proper covering and shielding of gonad, Assess skin exposure to fluorescent light, Proper position, Assess and adjust thermoregulation device, Promoting elimination and skin integrity and Monitoring bilirubin level. $92.7 \%$ of nurses have satisfactory knowledge scores regarding hyperbilirubinemia.

Table(8 ) As regard relation between personal \& socio-demographic data and nurses' knowledge regarding hyperbilirubinemia it is shown that Years of experience in NICU and Years of experience in other department have high significant as ** $P$ - value $\leq 0.01$ and Age / years $* * P$-value $\leq 005$ and for Training is significant $* P-$ value $\leq 05$

Table (1): Description of the study sample according to their personal and socio-demographical data $(n=41)$

\begin{tabular}{|c|c|c|c|}
\hline \multicolumn{2}{|l|}{ Personal and socio demographical Data } & n. & $\%$ \\
\hline \multirow{3}{*}{ Age / years } & $21-$ & 24 & 58.5 \\
\hline & $26-$ & 12 & 29.3 \\
\hline & $31-36$ & 5 & 12.2 \\
\hline \multicolumn{2}{|l|}{ Mean \pm SD } & \multicolumn{2}{|c|}{$25.8 \pm 4.3$ years } \\
\hline \multirow[t]{2}{*}{ Residence } & Urban & 15 & 36.6 \\
\hline & Rural & 26 & 63.4 \\
\hline \multirow[t]{4}{*}{ Years of experience in NICU } & Less than 1 year & 13 & 31.7 \\
\hline & $1-$ & 16 & 39 \\
\hline & $\geq 5$ & 12 & 29.3 \\
\hline & Mean \pm SD & \multicolumn{2}{|c|}{$3.3 \pm 3.8$ years } \\
\hline \multirow{4}{*}{ Years of experience in other department } & No previous & 18 & 43.9 \\
\hline & $<5$ & 20 & 48.8 \\
\hline & $\geq 5$ & 3 & 7.3 \\
\hline & Mean \pm SD & \multicolumn{2}{|c|}{$1.6 \pm 2.7$ years } \\
\hline \multirow[t]{2}{*}{ Training } & Yes & 29 & 70.7 \\
\hline & No & 12 & 29.3 \\
\hline \multirow[t]{2}{*}{ Marital status } & Single & 10 & 24.4 \\
\hline & Married & 31 & 75.6 \\
\hline \multirow[t]{2}{*}{ If married have children } & Yes & 28 & 90.3 \\
\hline & No & 3 & 9.7 \\
\hline
\end{tabular}


Table (2):+`3 Description of the nurses’ knowledge regarding to definition, causes, and manifestation of hyperbilirubinemia $(n=41)$

\begin{tabular}{|c|c|c|}
\hline Items & n. & $\%$ \\
\hline \multicolumn{3}{|l|}{ *Definition of hyperbilirubinemia } \\
\hline 1-Due to increase bilirubin level in the blood & 40 & 97.6 \\
\hline 2-Is a material causing yellowish discoloration & 9 & 22 \\
\hline 3-Is normal product of polycythemia & 35 & 85.4 \\
\hline 4-Red blood cells life span 120 days & 8 & 19.5 \\
\hline 5-Is deviation hemoglobin into hemo \& globin & 18 & 43.9 \\
\hline 6-In the normal, the liver discard excessive bilirubin before the labor & 25 & 61.0 \\
\hline $\begin{array}{l}\text { 7-In the first, the liver can't remove excessive bilirubin that lead to increase bilirubin } \\
\text { level and usually become in the } 2^{\text {nd }} \text { or } 3^{\text {rd }} \text { day }\end{array}$ & 40 & 97.6 \\
\hline \multicolumn{3}{|l|}{ *Causes } \\
\hline 1- Breast feeding & 24 & 58.5 \\
\hline 2-Breast milk appear at the end of $1^{\text {st }}$ week & 20 & 48.8 \\
\hline 3-Cephalohematoma & 30 & 73.2 \\
\hline 4-Sepsis or infection & 23 & 56.1 \\
\hline 5-Rh incompatibility & 35 & 85.4 \\
\hline 6-Deficiency in specific liver enzymes & 19 & 46.3 \\
\hline 7-Problem in the liver & 31 & 75.6 \\
\hline 8-Red blood cells abnormalities & 32 & 78 \\
\hline \multicolumn{3}{|l|}{ *Manifestation } \\
\hline 1-Yellowish discoloration in the skin & 41 & 100 \\
\hline 2-Yellowish discoloration in the sclera & 40 & 97.6 \\
\hline 3-Yellowish discoloration in the face, sclera, then all body & 32 & 78 \\
\hline
\end{tabular}

*Not equally distributed because of there was more than one selection.

Table (3) Description of the nurses' knowledge regarding to investigation done for hyperbilirubinemia\& bilirubin level $(n=41)$

\begin{tabular}{|l|l|l|}
\hline \multicolumn{1}{|c|}{ Items } & n. & \% \\
\hline *Investigation of hyperbilirubinemia & & \\
\hline 1-TSB \& direct \& indirect bilirubin level & 40 & 97.6 \\
\hline 2-Blood group & 31 & 75.6 \\
\hline 3-Complete blood count & 36 & 87.8 \\
\hline 4-Rh incomptaability & 15 & 36.6 \\
\hline Bilirubin level & & \\
\hline 1-Full term baby (more than 12 mg / dl ) in the 3 ${ }^{\text {rd }}$ day & 20 & 48.8 \\
\hline 2-Preterm baby (more than 15 mg / dl ) in the 3 ${ }^{\text {rd }}$ day & 20 & 48.8 \\
\hline 3-Unknown & 1 & 2.4 \\
\hline Total & $\mathbf{4 1}$ & $\mathbf{1 0 0}$ \\
\hline
\end{tabular}

*Not equally distributed because of there was more than one problem.

Table (4) Description of the nurses' knowledge regarding to therapeutic management for hyperbilirubinemia $(n=41)$

\begin{tabular}{|l|l|l|}
\hline Therapeutic management & $\mathbf{n .}$ & $\boldsymbol{\%}$ \\
\hline According to causes \&level of bilirubin may be & & \\
\hline 1-Conventional phototherapy, extensive phototherapy, blood exchange and breast feeding & 22 & 53.7 \\
\hline 2-Conventional phototherapy, blood exchange and breast feeding & 17 & 41.4 \\
\hline 3-Phototherapy and breast feeding & 2 & 4.9 \\
\hline Total & $\mathbf{4 1}$ & $\mathbf{1 0 0}$ \\
\hline
\end{tabular}

Table (5) Description of the nurses' knowledge regarding to complication for hyperbilirubinemia $(n=41)$

\begin{tabular}{|l|l|l|}
\hline *Complications & $\mathbf{n .}$ & \% \\
\hline 1-Fever & 14 & 34.1 \\
\hline 2-Paralysis & 11 & 26.8 \\
\hline 3-Vision disability & 36 & 87.8 \\
\hline 4-Hearing disability & 33 & 80.5 \\
\hline 5-Mental retardation & 38 & 92.7 \\
\hline
\end{tabular}

*Not equally distributed because of there was more than one problem. 
Table (6) Description of the nurses' knowledge regarding to phototherapy $(n=41)$

\begin{tabular}{|c|c|c|}
\hline Items & n. & $\%$ \\
\hline \multicolumn{3}{|l|}{ Definition of phototherapy } \\
\hline 1-Application of fluorescent light to the naked baby except genital organ and eye & 37 & 90.2 \\
\hline 2-Application of light to the naked baby except genital organ and eye & 4 & 9.8 \\
\hline Total & 41 & 100 \\
\hline \multicolumn{3}{|l|}{ *Minor side effect of phototherapy } \\
\hline 1-Bronzy baby syndrome & 39 & 95.1 \\
\hline 2-Greenish stool & 38 & 92.7 \\
\hline 3-Transient skin rashes & 38 & 92.7 \\
\hline 4-Hyperthermia & 40 & 97.6 \\
\hline 5-Increase metabolic rate & 39 & 95.1 \\
\hline 6-Dehydration & 39 & 95.1 \\
\hline 7-Electrolyte disturbance & 32 & 78 \\
\hline \multicolumn{3}{|l|}{ *Nursing care for infa nt receiving phototherapy } \\
\hline 1-Assure effective of phototherapy & 41 & 100 \\
\hline 2-Provide eye protection & 40 & 97.6 \\
\hline 3-Proper covering and shielding of gonad & 41 & 100 \\
\hline 4-Assess skin exposure & 41 & 100 \\
\hline 5-Proper position & 41 & 100 \\
\hline 6-Assess and adjust thermoregulation device & 41 & 100 \\
\hline 7-Promoting elimination and skin integrity & 41 & 100 \\
\hline 8-Hydration & 40 & 97.6 \\
\hline 9-Promoting infant parent interaction & 40 & 97.6 \\
\hline 10-Monitoring bilirubin level & 41 & 100 \\
\hline
\end{tabular}

*Not equally distributed because of there was more than one problem.

Table (7) Distribution total knowledge scores of nurses' regarding hyperbilirubinemia $(\mathrm{n}=41)$.

\begin{tabular}{|l|l|l|}
\hline Total knowledge scores & n. & \% \\
\hline -Satisfactory & 38 & 92.7 \\
\hline -Unsatisfactory & 3 & 7.3 \\
\hline Mean \pm S.D & $41.3 \pm 3.6$ & \\
\hline
\end{tabular}

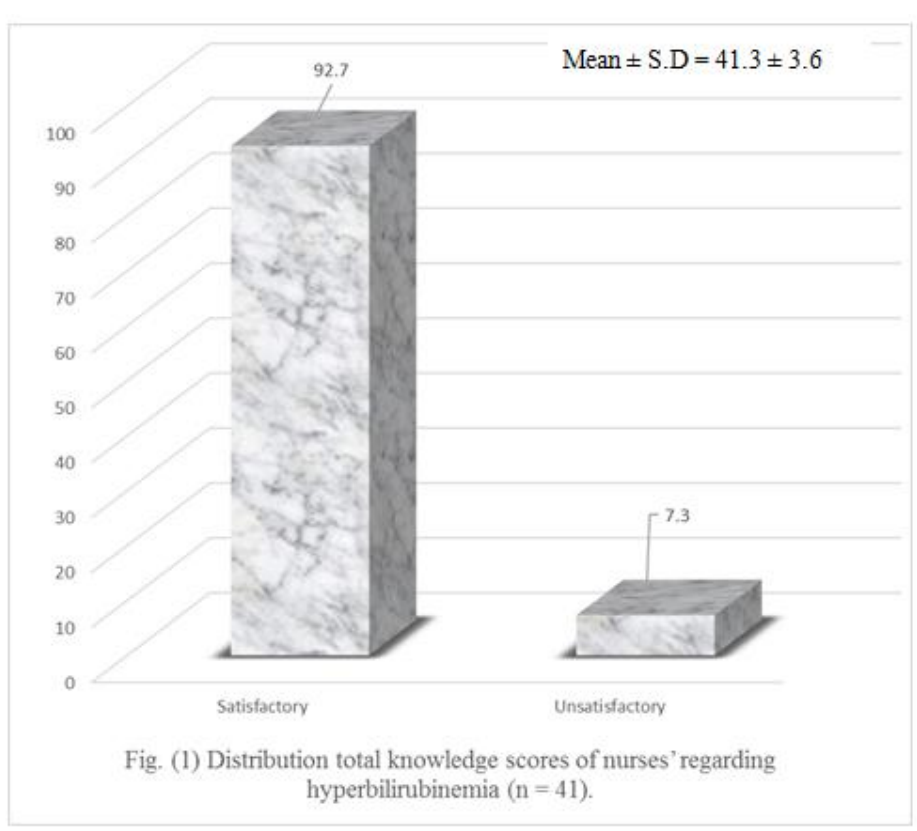


Table(8): relation between personal \& socio-demographic data and nurses' knowledge regarding hyperbilirubinemia $(\mathrm{n}=41)$.

\begin{tabular}{|c|c|c|c|c|c|c|c|}
\hline \multirow{3}{*}{\multicolumn{2}{|c|}{ Personal and Socio demographical data }} & \multicolumn{4}{|c|}{ Total knowledge scores } & \multirow{3}{*}{$\chi^{2}$} & \multirow{3}{*}{$P$ - value } \\
\hline & & \multicolumn{2}{|c|}{$\begin{array}{l}\text { Satisfying } \quad(n= \\
38)\end{array}$} & \multicolumn{2}{|c|}{$\begin{array}{l}\text { Unsatisfying }(\mathrm{n}= \\
3)\end{array}$} & & \\
\hline & & $\mathrm{n}$ & $\%$ & $\mathrm{~N}$ & $\%$ & & \\
\hline \multirow{3}{*}{ Age / years } & $21-$ & 23 & 60.5 & 1 & 33.3 & \multirow[t]{3}{*}{$\mathrm{t}=2.996$} & \multirow[t]{3}{*}{$.005^{* *}$} \\
\hline & $26-$ & 12 & 31.6 & 0 & .0 & & \\
\hline & $31-36$ & 3 & 7.9 & 2 & 66.7 & & \\
\hline \multirow[b]{2}{*}{ Residence } & Urban & 13 & 34.2 & 2 & 66.7 & \multirow[b]{2}{*}{1.262} & \multirow{2}{*}{$\begin{array}{l}.261 \\
\mathrm{NS}\end{array}$} \\
\hline & Rural & 25 & 65.8 & 1 & 33.3 & & \\
\hline \multirow{3}{*}{ Years of experience in NICU } & $<1$ year & 11 & 28.9 & 2 & 66.7 & \multirow{3}{*}{$\mathrm{t}=5.478$} & \multirow{3}{*}{$.001 * *$} \\
\hline & 5 & 15 & 39.5 & 1 & 33.3 & & \\
\hline & $\geq 5$ & 12 & 31.6 & 0 & .0 & & \\
\hline \multirow{3}{*}{$\begin{array}{l}\text { Years of experience in other } \\
\text { department }\end{array}$} & No previous & 17 & 44.7 & 1 & 33.3 & \multirow{3}{*}{$\mathrm{t}=3.866$} & \multirow{3}{*}{$.001 * *$} \\
\hline & $<5$ & 19 & 50 & 1 & 33.3 & & \\
\hline & $\geq 5$ & 2 & 5.3 & 1 & 33.3 & & \\
\hline \multirow[b]{2}{*}{ Training } & Yes & 28 & 73.7 & 1 & 33.3 & \multirow[t]{2}{*}{2.339} & \multirow[t]{2}{*}{$.05^{*}$} \\
\hline & No & 10 & 26.3 & 2 & 66.7 & & \\
\hline \multirow[t]{2}{*}{ Marital status } & Single & 10 & 26.3 & 0 & .0 & \multirow[t]{2}{*}{1.044} & .307 \\
\hline & Married & 28 & 73.7 & 3 & 100 & & NS \\
\hline \multirow[t]{2}{*}{ If married have children } & Yes & 25 & 89.3 & 0 & .0 & \multirow[t]{2}{*}{1.503} & .220 \\
\hline & No & 3 & 10.7 & 3 & 100 & & NS \\
\hline
\end{tabular}

\section{Discussion}

This study was designed to assess nurse's knowledge and practice on various aspects of knowledge and practice related to care of neonatal hyperbilirubinemia including recognition, causes, complications, treatment, and prevention and to identify the factors that influence knowledge of neonatal hyperbilirubinemia. The information obtained can be used to assist health care practitioners in designing educational programs to improve nurse's knowledge of neonatal hyperbilirubinemia.

Based on the results of the present study, more than one third the ages were below 26 years old with mean $25.8 \pm 4.3$ years. The results were in the same line with (Sâmara, 2013) who stated that; all study participants reported having age ranged from 25 to 35 years, thus showing up a group of young participants. The current study finding disagreed with (Mohamed et al., 2013) who mentioned that; nearly two third $(60 \%)$ of the nurses were 30 to less than 40 years old, with mean age were $31 \pm 6$. According to (Yadvendra, 2007) who reported that, the age of nurses are ranged from 20 to 40 years old.

In the present study about two third of nurses live in rural area and the more than two third of nurses are married and majority of married nurses have children. The results were in the same line with (Abd-alla, 2008) who observed that most of them were married. As regard years of experience, more than two third of them have experience less than 5 year. This finding is supported by (Watson, 2011) who mentioned that all participants the length of service ranged from 1 to 5 years. The current study finding disagreed with (Mohamed et al., 2013) who mentioned that; in relation to their years of experience in neonatal intensive care unit, the result reveals that the mean years of experience in NICU were 11.6 \pm 5.8 years.

According to (The British Association of Perinatal medicine, 2001) which stated that a lack of trained staff may lead to care that is unsafe and (Jeffery et al., 2004) \& (Vidal et al., 2001), stated that the implementation of effective training programs for health care providers in hospital settings followed by moderate improvement in Essential Newborn Care (ENC) is a must.While the finding was incongruent with another study (Mohamed, 2008) who revealed that the nurses' factors related to in-service training had no effect on both nurses' knowledge and performance.

Concerning previous training more than two third of nurses received previous training in neonatal care. The current study finding disagreed with (Mohamed et al., 2013) who found that only less than quarter of nurses have attended specific course/training in neonatology, and the majority of them did not attain any course or training.The current study showed that, nurses' knowledge about defines hyperbilirubinemia the majority of sample mentioned that increase bilirubin level in the blood. This reveals that the nurses' have a good knowledge for define hyperbilirubinemia. This finding is supported by (Salem, 2006) who showed that, half of the studied nurses gave correct responses when assessing their level of knowledge.

In my study the highest percentage of the nurses' said that, the causes of hyperbilirubinemia were Rh incompatibility. The current study finding disagreed with (Selahudin et al, 2011) who reported that; one fifth of the sample said that, hereditary disorders as the cause of jaundice, genetic disorders in bilirubin metabolism like Crigler Najjar syndromwhich is characterized by mild unconjugated hyperbilirubin could cause of jaundice. 
Regarding signs \& symptoms of hyperbilirubinemia, the present study mentioned that $100 \%$ of the nurses had knowledge about yellowish discoloration in the skin is manifestation of jaundice. According to (Ricci, 2008) who stated that, nursing care for the NBI with jaundice demands a comprehensive approach on the maternal and neonatal history and a detailed physical examination of the NBI, however. This fact is clear in the way how they report identifying jaundice, just due to the yellowish skin.

While (Santos et al., 2012) who mentioned the need for a judicious physical examination of the NBI, determination of weight and gestational age, and observation of the general status, the activity, the reflexes, the presence of visceromegalies, encephalic hematomas, and petechiae, the study of maternal history and breastfeeding for the NBI, trying to keep away the chance of infection. Laboratory tests are tools used to provide a good quality care.10 Thus, we find out that most study participants understand the clinical signs presented by the NBI affected by jaundice.

As regard complication majority of nurses' knowledge regarding to complication for hyperbilirubinemia, was vision disability and hearing disability. As regard (Brethauer \& Carey, 2010) who reported that, there is the need for nurses to be qualified and trained to perform early detection of jaundice, as a way to provide an adequate nursing care, aimed at clinical recovery and prevention of future complications of the newborn infant (NBI).

Concerning nurses' knowledge regarding to phototherapy majority of nurses defined phototherapy that is application of fluorescent light to the naked baby except genital organ and eye, the nurses have good knowledge about side effect of phototherapy hyperthermia.As regard nursing care for infant receiving phototherapy all of nurses have excellent knowledge such as assure effective of phototherapy, proper covering and shielding of gonad, assess skin exposure to fluorescent light, proper position, assess and adjust thermoregulation device, promoting elimination and skin integrity and monitoring bilirubin level. The majority of nurses have satisfactory knowledge scores regarding hyperbilirubinemia.

The results were in the same line with (Sâmara, 2013) who reported that, good quality care to the NBI with jaundice, the nurse needs to be aware of the procedures related to phototherapy, as well as undress the baby, protect her/his eyes with a dark blindfold, remove eye protection during bathing and diaper exchange, accurate water balance, observe frequency, appearance, and quantity of eliminations, check irradiance at each shift, and, where the focus is repositioned, check temperature every 2 or 3 hours, exchange decubitus every 2 hours, promote gastrointestinal motility, through feeding and stimulation of bowel movements, as well as observe changes in the skin exposed to the phototherapy, not using oily substances, lotions, or balsams.

As regard relation between personal \& socio-demographic data and nurses' knowledge regarding hyperbilirubinemia, it is shown that age, years of experience in NICU and training have high significant. Finally, it can be concluded that the majority of nurses have satisfactory level of knowledge about neonatal hyperbilirubinemia.

\section{Conclusion}

Based on the finding of the present study one can conclude that the highest percentage of nurses had satisfactory knowledge, while minority of nurses' had unsatisfactory score regarding hyperbilirubinemia in neonates. Also the majority of nurses' were competent regarding practices related to hyperbilirubinemia.

\section{Recommendation}

Establishment of in-service educational program to provide continuous education for nurses working in the neonatal intensive care units NICU aiming to refresh their knowledge, practice for care hyperbilirubinemia in neonates and for the new assigned nurses to improve their knowledge and practice.

\section{References}

[1]. Abai G, Henery J, Lian C B, Swee A W, Bili H, and Ratu I, (2011): Improving the Knowledge and Practice On Early Detection of Neonatal Jaundice by Nurses in Kuching District. International Journal of Public Health Research Special Issues, pp (92-99).

[2]. Abd-alla A, (2008): Impact of Health Education on Infection Control Measures in Operating Theater. Thesis Submitted for the Partial Fulfillment of Doctorial Degree in the Medical- Surgical Nursing Science. Tanta University. PP. 90

[3]. American Academy of Pediatrics (2004): Subcommitee on hyperbilirubinemia, management of hyperbilirubinemia in the Newborn Infant 35 or more weeks of gestation. Pediatr 2004; 114(1): 279-316.

[4]. Adebami O J, et al., (2015): Assessment of knowledge on causes and care of neonatal hyperbilirubenemia at the Nigerian primary and secondary health institutions. Int $J$ Res Med Sci Oct;3 (10 Page 2605-12. www.msjonline.org. Email: adebamiolusegun@gmail.com

[5]. Adebami O J (2011): Factors associated with the incidence of acute bilirubin encephalopathy in Nigerian population. J Pediatr Neurol;9:347-353.

[6]. Angel R G (2015): Study to assess the effectiveness of planned education on phototherapy among nursing students. Indian Journal of applied research, Medical science. volume 5(6). pp 632-34.

[7]. Brethauer M \& Carey L, (2010): Maternal experience with neonatal jaundice. MCN Am J Matern Child Nurs. 7; $35(1): 8-14$. Available from: http://www.ncbi.nlm.nih.gov/pubmed/20032753

[8]. Canadian pediatric society (2007): Position statement (F N 2007-02) guidelines for detections, management and prevention of hyperbilirubinemia in term and late preterm newborn infant (35 or more weeks gestation). Pediatr Child Health; 12:1B-12B. 
[9]. Mohamed S, Sabry Y. Y, Hamed M. S, Ebtisam M. and Ali T, (2013): Establishing Basic Standards of Nursing care protocol at Neonatal Intensive care unit. Nature and Science; 11(4). PP. $86: 92$.

[10]. The British Association of Perinatal Medicine, (2001): Standards for Hospitals providing neonatal intensive and high dependency care.2nd ed.

[11]. Jeffery H, \& Kocova M., (2004) .The impact of Evidence Based Education on Perinatal Capacity- Building Initiative in Macedonia, Medical Education; 38, PP. 435-447

[12]. Vidal S, Ronfani, \& Mello M, (2001): Comparison of Two Training Strategies for Essential Newborn Care in Brazil. Bulletin of the World Health Organization; 79(2): PP. 1024- 1031

[13]. Mohamed E, (2008): Assessment of Nurses' Knowledge and Performance Regarding Nursing Care given to Chronic Renal Failure Patient Under-goining Maintenance Hemodialysis. Thesis Submitted for the Partial Fulfillment of Master Degree in Medical Surgical Department Faculty of Nursing . Tanta University.PP. 55-62.

[14]. Salem A, (2006): Development of Nursing Practice Standards for Emergency Trauma Patients. Unpublished Doctoral Thesis in Critical Care Nursing. Faculty of Nursing, Alexandria University; PP. 120

[15]. Sâmara Duarte de Rosário, Ana Paula Nunes de Lima Fernandes, Lislane Karina da Silveira Lima, Maria Aldeíza da Silva, Francisca Waléria Barbosa, Akemi Iwata Monteiro, (2013): Nursing care for the newborn infant with jaundice in a maternity Hospital. J Nurs UFPE on line., Recife, 7(spe):PP. 7017-23.

[16]. Watson RL, (2011): Hyperbilirubinemia. Crit Care Nurs Clin North Am 21(1):97-120. Available from: http://www.ncbi.nlm.nih.gov/pubmed/19237047

[17]. Ricci SS, (2008): Enfermagem materno-neonatal e saúde da mulher. Rio de Janeiro: Guanabara Koogan.

[18]. Selahudin A, Derbew F. B, Palani S, \& Nashi M. J, (2011): Knowledge, attitude, perception toward jaundice Ayder among referral hospital health worker. 2 (12), PP. 191-195.

[19]. Watchko JF, Maisels JM. (2002): Neonatal Jaundice. Semin Neonatol 2002; 7: 101-3.

[20]. Slusher TM, Olusaniya BO. (2012): Neonatal hyperbilirubenemia in low- and middle-income countries. In: Stevenson DK, Maisels MJ, and Watchko JF. Care of the jaundiced neonate. New York: McGraw-Hill; 2012:263-73.

[21]. Su Yuen Ng and Jalan Pahang, (2014 ): What Do Mothers know about Neonatal Jaundice? Knowledge, Attitude and Practice of Mothers in Malaysia. Med J Malaysia Vol 69 No 6 December.Email: ngsy2002@yahoo.com

[22]. Queesland Maternity and Neonatal Clinical guidelines Program (2012): Neonatal jaundice : prevention, assessment and management. pp 3-20.

[23]. Su Yuen Ng and Jalan Pahang, (2014):What Do Mothers know about Neonatal Jaundice? Knowledge, Attitude and Practice of Mothers in Malaysia. Med J Malaysia Vol 69 No 6 December.

[24]. Yadvendra Goyaner, (2007): A study to Assess the Effectiveness of Structured Teaching Programme on Phototherapy for Neonatal Jaundice Among Staff Nurses in Selected Hospitals of Raichur. 